\title{
Application of weight-height relations for assessing adiposity in a United Kingdom offshore workforce
}

\author{
I M LIGHT, M G GIBSON \\ From the Robert Gordon's Institute of Technology, Offshore Survival Centre and Department of Mathematics \\ and Computing Studies, Aberdeen, UK
}

\begin{abstract}
Weight (W), height $(\mathrm{H})$, and skinfold thicknesses at biceps, triceps, subscapular, and suprailiac sites were measured in a United Kingdom offshore workforce. Weight and height were used to calculate $\mathrm{W} / \mathrm{H}$ relations. The percentage body fat was estimated from skinfold thicknesses and the correlations of adiposity with the various $\mathrm{W} / \mathrm{H}$ relations were evaluated. The significant increase in percentage body fat $(\% \mathrm{BF})$ with increasing age resulted in the development of age group specific regression equations relating $\% \mathrm{BF}$ to the indices of $\mathrm{W} / \mathrm{H}^{1.5}$ and $\mathrm{W} / \mathrm{H}^{2}$ (body mass index or Quetelet index). Little difference regarding the qualities of these two indices were detected in terms of poor correlation with height and strong correlation with weight. Thus either may be used with similar levels of confidence. Comparison with other studies, however, would be more easily accomplished if $\mathrm{W} / \mathrm{H}^{2}$ were used. In the absence of skinfold thickness measurements the $\mathrm{W} / \mathrm{H}^{2}$ could readily be implemented during a routine medical and applied for the estimation of $\% \mathrm{BF}$ in the offshore population provided that the appropriate regression equation were used and that the limitations of the technique are recognised. Percentage values for $\mathrm{W}, \mathrm{H}, \mathrm{W} / \mathrm{H}$ relations, and $\% \mathrm{BF}$ by age group are provided for comparison with other population studies.
\end{abstract}

The advent of offshore exploration, construction, and subsequent production has resulted in a large number of men and to a lesser degree, some women, being employed in unusual circumstances. Owing to the distance between the worksite and the mainland it is typically necessary for the workforce to become temporary residents of these offshore installations and structures. The employees may therefore spend weeks or multiples of a week on location and often working rotas necessitating 12 hour shifts of alternate work and rest. It has recently been suggested that fishermen and offshore workers may be heavier and possess a higher percentage of body weight as fat. ${ }^{1}$ While endowing an enhanced insulation against heat loss and prolongation in survival time against hypothermia in the event of accidental cold water immersion, the possible deleterious effects of increased levels of body fat and obesity must be considered. The inverse relation between percentage body fat and aerobic performance ${ }^{2}$ and hence physical working capacity is well established. ${ }^{3}$ Furthermore, the health con-

Accepted 28 May 1986 sequences of overweightness and obesity have been extensively reported. ${ }^{4}$

Commercial diving is one occupation that has received considerable interest with regard to body weight and adiposity. ${ }^{5-7}$ The medical examination of commercial divers for work in the North Sea follows the scheme devised by the Underwater Engineering Group of the Construction Industry Research and Information Association (CIRIA). As reported by McCallum and Petrie, ${ }^{6}$ obesity is one of the factors taken into consideration in deciding whether or not a man is medically fit to drive. ${ }^{6}$ Other studies have shown that a high degree of adiposity may predispose towards decompression sickness. ${ }^{8-10}$ At present numerous techniques may be used in routine medical examinations to help provide more quantitative measures of overweightness and obesity than simply utilising the body weight. Height and weight and, to a lesser extent, skinfold thicknesses are routinely measured during diving medical examinations and usually in the medical examination of non-diving offshore personnel.

The use of weight $(\mathrm{W})$ to height $(\mathrm{H})$ relations has been reported for many populations, particularly 
relating to young military ${ }^{2}$ and civilian groups. ${ }^{11}$ The application of weight/height relations in assessing obesity has received considerable attention. ${ }^{12}$ One index that is often used in adult men as a measure of adiposity is the Quetelet $\left(\mathrm{W} / \mathrm{H}^{2}\right)$ or body mass index. Garrow has established levels of the body mass index commensurate with varying degrees of overweightness and adiposity. ${ }^{13}$ The indices of adiposity are easily calculated, requiring nothing more than the height and weight of an individual. They include $\mathrm{W} / \mathrm{H}$ itself, $\mathrm{W} / \mathrm{H}^{2}, \mathrm{~W} / \mathrm{H}^{3}$ (the Rohr index ${ }^{11}$ ), $\mathrm{W}^{\mathbf{0} 33} / \mathrm{H}$ (the Ponderal index ${ }^{11}$ ), and $H / W^{0.33}$ (Sheldon's ${ }^{14}$ inversion of the Ponderal index).

The usefulness of various $\mathrm{W} / \mathrm{H}$ relations as measures of obesity has been discussed by Keys et al who concluded that the $\mathrm{W} / \mathrm{H}^{2}$ index was the most satisfactory since this index had a significant correlation with body fat and a low correlation with height. ${ }^{12}$ Benn has given additional criteria of optimality for a "good" index of obesity 15 : (1) it should be highly correlated with measures of relative adiposity and (2) its distribution should be independent of height. Benn also showed that for various values of $p$ for the index of the form $\mathrm{W} / \mathrm{H}^{\mathrm{p}}$ that there is a zero correlation of $\mathrm{W} / \mathrm{H}^{1.65}$ with $\mathrm{H}$, but that in the range $1.4 \leqslant \mathrm{p} \leqslant 2.0$, all indices $\mathrm{W} / \mathrm{H}^{\mathrm{p}}$ have a low correlation with $\mathrm{H}^{15}$ The choice of a weight for height index should be based on the actual group studied with $p$ being chosen from the sample by regression methods if the sample is sufficiently large or an integer form of $\mathrm{W} / \mathrm{H}^{\mathrm{p}}$ to make computation easy. Nevertheless, for whichever $p$ value is chosen, checks should be made that the index is independent from height.

The percentage overweight is another method that has been used in assessing obesity. This value is calculated from the patient's body weight compared with the equivalent standard weight for individuals of the same sex, height, and age listed in the tables of the Metropolitan Life Insurance Company. ${ }^{16}$ These widely used tables have now been superseded by a

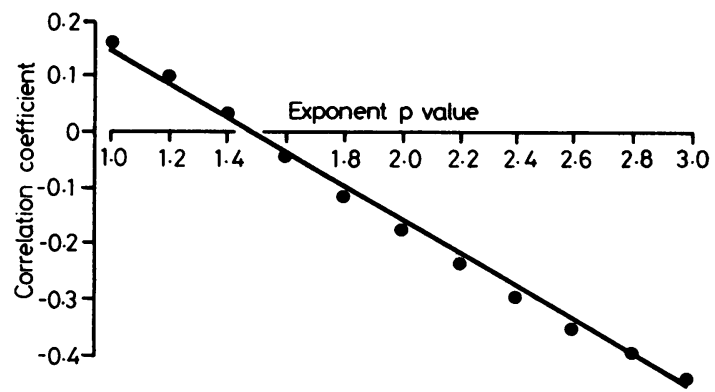

Fig 1 Benn plot of the correlation coefficient of height versus $W / H^{p}$ for various values of $p .{ }^{15}$ " $X$ " axis intercept gives population specific value of about $1 \cdot 5$. revised 1983 version. The values quoted in these tables refer to measurements taken wearing both assessing overweightness has been questioned. ${ }^{6}$ There is a requirement to provide appropriate data on $\frac{}{0}$ height and weight of the offshore population and how $\bar{\omega}$ these simple measurements may be related to esti- $\overparen{\nabla}$ mates of overweightness and fatness.

The objectives of the present study were to report is values of weight and height and to determine a $\vec{\circ}$ weight/height ratio applicable to the offshore popu- lation that satisfies the selection criteria for such an $\vec{\omega}$ index and that may be readily determined in a routine medical examination.

\section{Methods}

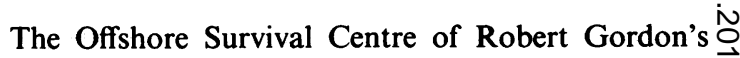
Institute of Technology provides training in maritime $\overrightarrow{0}$ survival for the offshore and oil related industries. In a typical week some 350 trainees attend a variety of $\vec{z}$ courses of varying durations between one and five days. The Offshore Survival Centre is, therefore, $\stackrel{?}{\supset}$ ideally placed to undertake population surveys and $\vec{\theta}$

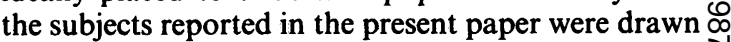
from a workforce engaged in the British sector of the North Sea in 1984.

\section{Subjects}

The subjects were selected from the course registers $\stackrel{\odot}{\complement}$ and every tenth person was asked to participate in the $\overrightarrow{\vec{A}}$ study. A sample of 419 adult male white United King- 3 dom residents currently engaged in offshore employ- $\bar{Z}$ ment were measured.

\section{Procedures}

The subjects were assembled in groups and asked to void their bladders and to defecate. A questionnaire $\delta$ was then completed regarding age, current $₹$ occupation, and years in offshore employment. 0 Height $(\mathrm{H})$ and weight $(\mathrm{W})$ were assessed with the subjects wearing only underpants. $(\mathrm{H})$ was measured barefoot to $0.5 \mathrm{~cm}$ with a wall mounted anthropometer and (W) was read to the nearest $0.1 \mathrm{~kg}$ using of a calibrated Weylux beam balance. Skinfold mea- N surements were taken with the Harpenden caliper $N$ (British Indicators Ltd) from biceps, triceps, and sub- $\sigma$ scapular and suprailiac sites as described by Durnin and Womersley. ${ }^{17}$ Percentage body weight as fat $\stackrel{0}{=}$ (\%BF) was then calculated from the sum of the skin- $\cong$ fold thicknesses using age related coefficients for body density ${ }^{17}$ and substituted in the Siri equation. ${ }^{18}$

The correlation relation of $\mathrm{W} / \mathrm{H}^{\mathrm{p}}$ with $\mathrm{H}$ was then investigated by choosing values of $p$ in the range 1.0 
Table 1 Physical characteristics, indices of adiposity, and skinfold thicknesses of the sample population $(n=419)$

\begin{tabular}{lccr}
\hline Variable & Mean & SD & \multicolumn{1}{l}{ Range } \\
\hline Age (years) & 32.5 & 8.2 & $18.0-57.0$ \\
Weight (kg) & 76.5 & 9.9 & $53.0-115.2$ \\
Height (m) & 1.75 & 0.07 & $1.58-2.0$ \\
Biceps (mm) & 6.6 & 2.8 & $2.9-19.2$ \\
Triceps (mm) & 13.0 & 5.0 & $4.9-35.2$ \\
Subscapular (mm) & 18.8 & 8.2 & $7.2-51.0$ \\
Suprailiac (mm) & 31.9 & 10.5 & $5.9-53.0$ \\
Sum of skinfold (mm) & 70.3 & 23.4 & $22.6-133.3$ \\
\hline
\end{tabular}

to 3.0 to determine the index which gave zero correlation and by regressing log height on log weight (a linear relation) with $\mathrm{p}$ being the gradient. From the correlation $p=1.47$ and from regression $p=1.49$ which agrees with Benn's findings ${ }^{15}$ (see fig 1). This suggests that the height $(\mathrm{H})$ should be raised to the power of approximately $1 \cdot 5$. The $\mathrm{W} / \mathrm{H}^{1 \cdot 5}$ relation was then included for comparison.

\section{Results}

Table 1 shows the physical characteristics of the subjects. The mean age of the sample population was 32.5 (SD 8.2) years and the subjects had been engaged in offshore employment in the United Kingdom sector for an average of 4.3 years. Table 2 shows weight, height, and $\mathrm{W} / \mathrm{H}$ relations including $\mathrm{W} / \mathrm{H}^{1 \cdot 5}$. The percentage body fat is shown as percentiles by the age groups 20-29, 30-39, 40-49 (table 3). The percentage $\mathrm{BF}$ for the sample population is plotted against age in fig 2. Linear regression analysis showed a highly significant correlation coefficient of $0.65(t=17.7$; p 0.0001). The regression analysis produced a regression equation of the form $\% B F=0.442$ (age)
Table 3 Percentile distributions of percent body fat by age group (subjects below' age 20 and above 50 are not included)

\begin{tabular}{|c|c|c|c|}
\hline \multirow[b]{2}{*}{ Percentile } & \multicolumn{3}{|c|}{ Age group (years) } \\
\hline & $\begin{array}{l}20-29 \\
(n=180)\end{array}$ & $\begin{array}{l}30-39 \\
(n=144)\end{array}$ & $\begin{array}{l}40-49 \\
(n=77)\end{array}$ \\
\hline $\begin{array}{r}1 \\
2 \\
5 \\
10 \\
20 \\
25 \\
30 \\
40 \\
50 \\
60 \\
70 \\
75 \\
80 \\
90 \\
95 \\
98 \\
99\end{array}$ & $\begin{array}{l}11 \cdot 3 \\
12.3 \\
13.8 \\
15 \cdot 1 \\
17.3 \\
18.1 \\
18 \cdot 5 \\
19.7 \\
21.0 \\
22.3 \\
23.9 \\
24.9 \\
25.7 \\
27.2 \\
28.4 \\
29.7 \\
30.4\end{array}$ & $\begin{array}{l}15.5 \\
16.7 \\
18.5 \\
19.6 \\
22.2 \\
22.8 \\
23.3 \\
24.6 \\
25.5 \\
26.2 \\
27.0 \\
27.6 \\
27.9 \\
28.8 \\
29.5 \\
31.1 \\
31.4\end{array}$ & $\begin{array}{l}18 \cdot 3 \\
21 \cdot 6 \\
22 \cdot 1 \\
23 \cdot 7 \\
26 \cdot 7 \\
28 \cdot 1 \\
28 \cdot 6 \\
29 \cdot 4 \\
30 \cdot 6 \\
31 \cdot 9 \\
33 \cdot 0 \\
33 \cdot 5 \\
34 \cdot 2 \\
34 \cdot 9 \\
36 \cdot 2 \\
38 \cdot 0 \\
38.1\end{array}$ \\
\hline $\begin{array}{l}\text { Mean } \\
\text { SD }\end{array}$ & $\begin{array}{r}21 \cdot 2 \\
4 \cdot 6\end{array}$ & $\begin{array}{r}25 \cdot 0 \\
3.5\end{array}$ & $\begin{array}{r}30 \cdot 4 \\
4 \cdot 3\end{array}$ \\
\hline
\end{tabular}

$+10 \cdot 225$. Further linear regression analysis resulted in the correlation coefficient matrix for height and weight with the selected $\mathrm{W} / \mathrm{H}$ relations (table 4 ). The ratio $\mathrm{W} / \mathrm{H}^{1 \cdot 5}$ showed the least correlation with height and, with the exception of $\mathrm{W} / \mathrm{H}$, the greatest correlation with weight

Since the relation between the increase in \%BF with age was significant the subjects were divided in the three age groups shown in table 3 . The detailed correlation coefficient matrix, obtained by linear regression analysis, relating the $\% \mathrm{BF}$ in each group to the height, weight, and $\mathrm{W} / \mathrm{H}$ relation is recorded in table 5. Regression equations for predicting \%BF

Table 2 Percentile distributions of weight/height indices $(n=419) . W=$ weight in kilograms; $H=$ height in metres

\begin{tabular}{|c|c|c|c|c|c|c|c|}
\hline Percentile & $\boldsymbol{W}$ & $H$ & $\boldsymbol{W} / \boldsymbol{H}$ & $W / H^{1 \cdot 5}$ & $W / H^{2}$ & $W / H^{3}$ & $W^{0.33} / H$ \\
\hline $\begin{array}{r}1 \\
2 \\
5 \\
10 \\
20 \\
25 \\
30 \\
40 \\
50 \\
60 \\
70 \\
75 \\
80 \\
90 \\
95 \\
98 \\
99\end{array}$ & $\begin{array}{r}55 \cdot 1 \\
58.9 \\
61 \cdot 8 \\
64 \cdot 1 \\
67.9 \\
68.9 \\
71 \cdot 0 \\
74.0 \\
76 \cdot 1 \\
78.5 \\
81 \cdot 1 \\
82.7 \\
84.7 \\
88.8 \\
93.2 \\
99.0 \\
105.3\end{array}$ & $\begin{array}{l}1.61 \\
1.62 \\
1.64 \\
1.67 \\
1.69 \\
1.70 \\
1.72 \\
1.73 \\
1.75 \\
1.77 \\
1.79 \\
1.80 \\
1.81 \\
1.84 \\
1.87 \\
1.90 \\
1.92\end{array}$ & $\begin{array}{l}32 \cdot 94 \\
34 \cdot 55 \\
35 \cdot 73 \\
37 \cdot 18 \\
38 \cdot 88 \\
39 \cdot 87 \\
40 \cdot 46 \\
41 \cdot 86 \\
43 \cdot 33 \\
44 \cdot 67 \\
45 \cdot 92 \\
46 \cdot 84 \\
47 \cdot 87 \\
49 \cdot 94 \\
52 \cdot 20 \\
55 \cdot 55 \\
56 \cdot 90\end{array}$ & $\begin{array}{l}25 \cdot 73 \\
26 \cdot 35 \\
27 \cdot 00 \\
28 \cdot 07 \\
29 \cdot 48 \\
29 \cdot 89 \\
30 \cdot 56 \\
31 \cdot 47 \\
32 \cdot 71 \\
33 \cdot 41 \\
34 \cdot 95 \\
35 \cdot 44 \\
36 \cdot 02 \\
37 \cdot 84 \\
39 \cdot 47 \\
42 \cdot 26 \\
43 \cdot 38\end{array}$ & $\begin{array}{l}19.34 \\
19.95 \\
20.45 \\
20.99 \\
22.28 \\
22.81 \\
23.06 \\
23.66 \\
24.61 \\
25 \cdot 25 \\
26 \cdot 31 \\
26.82 \\
27 \cdot 18 \\
28.60 \\
30.02 \\
32.04 \\
32.94\end{array}$ & $\begin{array}{l}10.52 \\
10.88 \\
11.45 \\
11.87 \\
12.62 \\
12.83 \\
13.03 \\
13.53 \\
13.91 \\
14.40 \\
14.90 \\
15.20 \\
15.76 \\
16.78 \\
17.62 \\
18.67 \\
19.04\end{array}$ & $\begin{array}{l}2 \cdot 16 \\
2 \cdot 18 \\
2 \cdot 22 \\
2 \cdot 25 \\
2 \cdot 29 \\
2 \cdot 31 \\
2 \cdot 32 \\
2 \cdot 35 \\
2 \cdot 37 \\
2 \cdot 39 \\
2 \cdot 43 \\
2 \cdot 44 \\
2 \cdot 47 \\
2 \cdot 52 \\
2 \cdot 56 \\
2 \cdot 61 \\
2 \cdot 63\end{array}$ \\
\hline $\begin{array}{l}\text { Mean } \\
\text { SD }\end{array}$ & $\begin{array}{r}76.5 \\
9.9\end{array}$ & $\begin{array}{l}1.75 \\
0.07\end{array}$ & $\begin{array}{r}43 \cdot 60 \\
5 \cdot 20\end{array}$ & $\begin{array}{r}32.90 \\
3.90\end{array}$ & $\begin{array}{r}24.80 \\
2.90\end{array}$ & $\begin{array}{r}14.20 \\
1.90\end{array}$ & $\begin{array}{l}2 \cdot 38 \\
0.10\end{array}$ \\
\hline
\end{tabular}




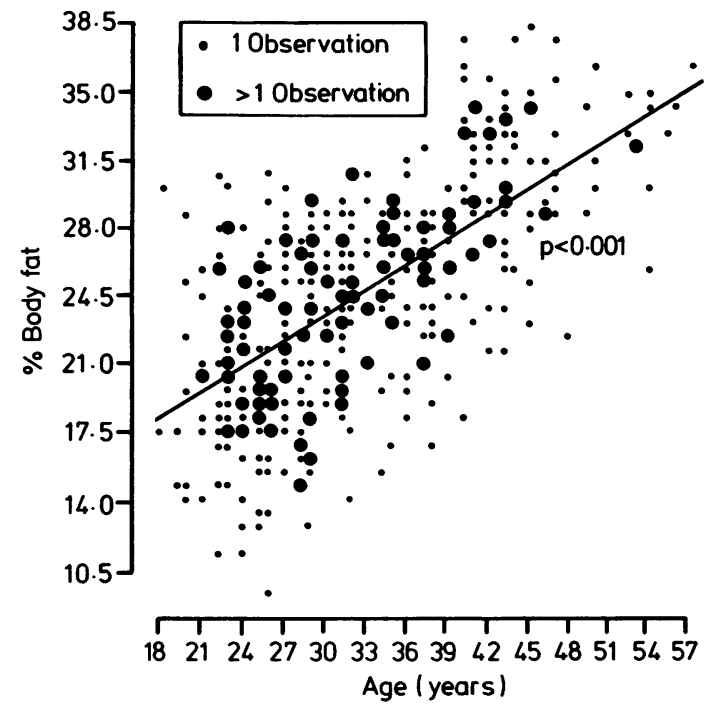

Fig 2 Increase in percentage body fat $(\% B F)$ shown against age. Regression equation of form $\% B F=$ $0.442($ age $)+10.225$ was obtained $(t=17.7 ; p<0.0001)$.

from $\mathrm{W} / \mathrm{H}$ indices were developed for each age group and shown in table 6 . The correlation coefficients relating to $\mathrm{W} / \mathrm{H}^{1.5}$ and $\mathrm{W} / \mathrm{H}^{2}$ were similar in each respective age group, although the coefficient increased directly with the increase in age.

The $r^{2}$ values shown in table 6 show that the percentage of the total variation that may be explained by the regression models is remarkably similar for both $\mathrm{W} / \mathrm{H}^{1.5}$ and $\mathrm{W} / \mathrm{H}^{2}$. The standard error of the estimate for the value of $\% \mathrm{BF}$ predicted from the mean value for each index for the respective age groups (see table 6) indicates the lack of difference in terms of accuracy between the indices.

\section{Discussion}

At present, commercial divers are the only group of employees within the North Sea population for whom recommendations regarding degree of overweightness and obesity exists. Since the offshore population is aging and has been shown to be both significantly

Table 4 Correlation coefficient of indices of adiposity with height $(\mathrm{H})$ and weight $(\mathrm{W})$

\begin{tabular}{lrr}
\hline & \multicolumn{1}{l}{} & \multicolumn{1}{l}{$W$} \\
\hline$W / H^{1.5}$ & 0.15 & 0.96 \\
$W / H^{1 \cdot 5}$ & -0.01 & 0.89 \\
$W / H^{2}$ & -0.17 & 0.81 \\
$W / H^{3}$ & -0.44 & 0.61 \\
$W^{0.33} / H$ & -0.45 & 0.60 \\
$H^{3} / W^{0.33}$ & 0.46 & -0.60 \\
\hline
\end{tabular}

Table 5 Correlation coefficients of percent body fat with height $(H)$, weight $(W)$, and indices of adiposity for each age group

\begin{tabular}{llll}
\hline \multicolumn{3}{c}{ Age group (years) } \\
\cline { 2 - 4 } & $\begin{array}{l}20-29 \\
(n=180)\end{array}$ & $\begin{array}{l}30-39 \\
(n=144)\end{array}$ & $\begin{array}{c}40-49 \\
(n=77)\end{array}$ \\
\hline $\mathrm{H}$ & -0.07 & -0.12 & -0.03 \\
$\mathrm{~W}$ & 0.63 & 0.63 & 0.69 \\
$\mathrm{~W} / \mathbf{H}^{1.5}$ & 0.73 & 0.74 & 0.77 \\
$\mathrm{~W} / \mathbf{H}^{1.5}$ & 0.76 & 0.77 & 0.80 \\
$\mathrm{~W} / \mathbf{H}^{2}$ & 0.77 & 0.78 & 0.80 \\
$\mathrm{~W} / \mathbf{H}^{3}$ & 0.73 & 0.73 & 0.76 \\
$\mathrm{~W}^{0.33} / \mathrm{H}$ & 0.73 & 0.74 & 0.77 \\
\hline
\end{tabular}

fatter and more overweight ${ }^{19}$ then to apply a single regression equation would be erroneous.

During routine medical examination, height and $\stackrel{N}{\circ}$ weight are normally recorded and perhaps an esti- 0 mate of overweightness/obesity either from weight for height or by subjective assessment. Rarely are skin- $\vec{z}$ fold thicknesses, underwater weighing, whole body potassium, or other indices of body composition $\frac{\rho}{\partial}$ used. Many of these techniques are both complex and $\vec{\theta}$ time consuming and do not lend themselves to incor- $\infty$ poration as part of the routine medical. As height and weight may easily be measured the accuracy of such measurements and their incorporation into an index of adiposity may be useful.

The definite increase in percentage body fat with age suggests that if an index is to be used, it is perhaps $\stackrel{\AA}{\perp}$ better to use a series of regression equations that are $\overrightarrow{\vec{A}}$ age specific. In addition to determining the age $\frac{3}{3}$ specific regression equations regarding which $\mathrm{W} / \mathrm{H} \supsetneq$ relation is applicable - that is, the power exponent for (H) - each age category should have a specific regression equation.

The $\log / \log$ plot according to Benn showed that the exponent $\mathrm{p}$ for the study population should be $1 \cdot 5 .{ }^{15} 3$. An interesting value since instead of applying W/ $\mathrm{H}^{2} \dot{8}$ in studies of women a value of 1.5 has also been considered more appropriate. It is well known that $\mathrm{O}$ women have a higher percentage body weight as fat and the subjects in the present study also showed $\frac{T}{O}$ higher percentage body fat content than their onshore peers. $^{19}$

The choice of which $\mathrm{W} / \mathrm{H}$ index is the most appli- $N$ cable to the reported population may be decided from $\mathrm{N}$ the correlation coefficients relating the $\mathrm{W} / \mathrm{H}$ indices to $\omega$ height and weight (table 4). Since any $\mathrm{W} / \mathrm{H}$ index requires a poor correlation with height and a strong $\stackrel{\circ}{\subset}$ correlation with weight with the exception of $\mathrm{W} / \mathrm{H} \Phi$ itself the smallest height correlation was shown with? $\mathrm{W} / \mathrm{H}^{1 \cdot 5}$ and $\mathrm{W} / \mathrm{H}^{2}$. Furthermore, these two, indices also showed the strongest correlations with weight. In addition, the strongest positive correlations relating 
Table 6 Regression equations for the prediction of percentage body fat ( $\% B F)$ from $W / H$ indices. (Standard error of the estimate ( $S E E$ ) is calculated for the respective mean index value)

\begin{tabular}{|c|c|c|c|}
\hline & \multicolumn{3}{|l|}{ Age group (years) } \\
\hline & $20-29$ & $30-39$ & $40-49$ \\
\hline $\begin{array}{l}\mathrm{W} / \mathrm{H}^{1 \cdot 5}\left(\mathrm{Kg}^{1 \cdot 5}\right) \\
\mathrm{SEE} \\
\mathrm{r}^{2}(\% \text { variation }) \\
\mathrm{W} / \mathrm{H}^{2}\left(\mathrm{Kg}^{2}\right) \\
\text { SEE } \\
\mathrm{r}^{2}(\% \text { variation })\end{array}$ & $\begin{array}{l}\% \mathrm{BF}=0.968\left(\mathrm{~W} / \mathrm{H}^{1.5}\right)-9.473 \\
2.964 \\
58 \cdot 0 \\
\% \mathrm{BF}=1.298\left(\mathrm{~W} / \mathrm{H}^{2}\right)-9.717 \\
2.914 \\
60.0\end{array}$ & $\begin{array}{l}\% \mathrm{BF}=0.778\left(\mathrm{~W} / \mathrm{H}^{1.5}\right)-0.801 \\
2.249 \\
60.0 \\
\% \mathrm{BF}=1.017\left(\mathrm{~W} / \mathrm{H}^{2}\right)-0.570 \\
2.218 \\
61.0\end{array}$ & $\begin{array}{l}\% \mathrm{BF}=0.797\left(\mathrm{~W} / \mathrm{H}^{1.5}\right)+2.622 \\
2.612 \\
64.0 \\
\% \mathrm{BF}=1.058\left(\mathrm{~W} / \mathrm{H}^{2}\right)+2.454 \\
2.582 \\
64.0\end{array}$ \\
\hline
\end{tabular}

the indices to percentage body fat were detected for $\mathrm{W} / \mathrm{H}^{1 \cdot 5}$ and $\mathrm{W} / \mathrm{H}^{2}$ (table 5 ).

Since little difference was shown between $\mathrm{W} / \mathrm{H}^{1 \cdot 5}$ and $\mathrm{W} / \mathrm{H}^{2}$ it appears that either relation may be used to describe the offshore population. In practical terms $\mathrm{W} / \mathbf{H}^{2}$ is both easier to calculate and would readily lend itself to comparison with other studies where extensive use has been made of the body mass index.

The index of $\mathrm{W} / \mathrm{H}^{2}$ would indeed seem to be the most appropriate index of adiposity that should be applied to the offshore workforce. Since height in metres and weight in kilograms is easily obtained without the requirement for either complicated apparatus or sophisticated technique then $\mathrm{W} / \mathrm{H}^{2}$ may be used as a measure of adiposity for the workforce reported and in the absence of skinfold thickness measurements then the age specific regression equations may be used to predict the percentage body fat. The accuracy of such a technique having being established is shown in table 6 .

If such a method of assessment of adiposity were adopted the acknowledged limitations of the application of $\mathrm{W} / \mathrm{H}$ indices should be appreciated. The well known account of the United States athletes who would not have been passed fit for military service because of an unacceptably high value of adiposity from height and weight measurements should be remembered. ${ }^{20}$ Weight/height indices have the distinct disadvantages that they do not differentiate the moderately obese from muscular individuals nor do they take into account the changing body composition that occurs with aging. The partitioning of the body mass into lean body mass and percentage body fat would appear valuable. If the limitations and advantages are accepted then $\mathrm{W} / \mathrm{H}^{2}$ would seem to be the most applicable $\mathrm{W} / \mathrm{H}$ index for the population measured in the current study.

\section{References}

1 Hayward JS, Eckerson JD. Physiological responses and survival time prediction for humans in ice-water. Aviat Space Environ Med 1984;55:206-15.

2 Knapik JJ, Burse RL, Vogel JA. Height, weight, percent body fat and indices of adiposity for young men and women entering the US Army. Aviat Space Environ Med 1983;54:223-31.
3 Le Blanc J, Nadeau A, Boulay N, Rousseau-Mignerson S. Effects of physical training and adiposity on glucose metabolism and 125I- insulin binding. $J$ Appl Physiol 1979;46:235-9.

4 Royal College of Physicians of London. Obesity report. London: RCP, 1983.

5 Dembert NL, Jekel JF. Mooney LW. Weight-height indices and percent body fat among US Navy divers. Aviat Space Environ Med 1984;55:391-5.

6 McCallum RI, Petrie A. Optimum weights for commercial divers. Br J Ind Med 1984;41:275-8.

7 Thompson J, Barr D, McDonald DR, Rennie MJ. North Sea divers are no fitter than sedentary men. Lancet 1984;i:52.

8 Dembert ML. Risk factors for the development of decompression sickness amongst US Navy divers. Newhaven CI: Yale University School of Medicine (department of epidemiology and public health), 1983. (Master's thesis.)

9 Gray JS. Constitutional factors affecting susceptibility to decompression sickness. In: Fulton J, ed. Decompression sickness. Philadelphia: WB Saunders, 1951:182-91.

10 Hayashi K. Medical survey on 299 helmet divers. Thira joint meeting of the panel on diving physiology and technology. United States-Japan conference on development and utilization of natural resources, Tokyo, 1975. Tokyo: University of Tokyo, 1975: 38-9.

11 Womersley J, Durnin JVGA. A comparison of the skinfold method with extent of overweight and various weight-height relationships in the assessment of obesity. $B r J$ Nutr 1977;38:271-84

12 Keys A, Fidanza F, Karvonen MJ, Kimura N, Taylor HL. Indices of relative weight and obesity. $J$ Chronic Dis 1972;25:329-43.

13 Garrow JS. Obesity and energy exchange. In: Dawson AM, Compston N, Besser GM, eds. Recent advances in medicine. Edinburgh and London: Churchill Livingstone, 1981:75-92.

14 Sheldon WH, Stephens SS, Tucker CB. The varieties of human physique: an introduction to constitutional psychology. New York: Harper, 1940.

15 Benn RT. Some mathematical properties of weight-for-height indices used as measures of adiposity. Br J Prev Soc Med 1971;25:42-50.

16 Society of Actuaries. Build and blood pressure study. Vol I. Chicago: Society of Actuaries, 1959:16-29.

17 Durnin JVGA, Womersley J. Body fat assessed from total body density and its estimation from skinfold thickness: measurements on 481 men and women aged from 16-72 years. $B r J$ Nutr 1974;32:77-97.

18 Siri WE. Body volume measurement by gas dilution. In: Brozek J, Henschel A, eds. Techniques for measuring body composition. Washington DC: National Academy of Science, National Research Council, 1961:108-17.

19 Light IM, Gibson M. Percentage body fat and prevalence of obesity in a United Kingdom Offshore Population. Br J Nutr 1986;56:97-104.

20 Behnke AR, Feen BG, Welham WC. The specific gravity of healthy men: body weight divided by volume as index of obesity. JAMA 1942;118:495-8. 